\title{
Exercising soft closure on lay health knowledge? Harnessing the declining power of the medical profession to improve online health information
}

\begin{abstract}
This study aims to address the increasingly complex medical predicament of low quality online health information contributing to lay health knowledge and consequently to clinical outcomes. We situate the predicament within a social change paradigm of individualism, choice, diminishing medical power, and emergence of the legitimacy of lay health knowledge. We contend that the prominence of lay health knowledge has been facilitated by the internet, and is due to a surge in broadcasting of experiential knowledge coupled with increased access to and enactment of medical and non-medically sanctioned online information on health and illness. We draw on and further test the application of social closure theory to help conceive a potential solution to this enduring problem. We conduct a quality assessment of an indicative case study, Apicectomies, and test the application of our notion of soft closure on its findings, resulting in targeted, feasible and potentially beneficial solutions to increasing the medical quality of online health information. We further present the extant application of soft closure by Healthtalkonline.org, which collates a medically reliable set of experiential knowledge on a range of health issues. As such, we propose a constructive re-enactment of the traditional closure of the medical profession on medical knowledge.
\end{abstract}


Abstract word count: 201

Keywords: lay knowledge; closure; online health information; medical profession; health information seeking; patient-provider communication 


\section{Introduction}

Internet use has rapidly expanded since the turn of the millennium, with a worldwide estimated usage of over 3 billion people (ITU, 2014). A 2013 Pew survey reported $87 \%$ of U.S. adults using the internet, $72 \%$ of whom looked online for health information (Fox and Duggan, 2013). Similarly, the Oxford Internet study (Dutton and Blank, 2013) suggests that 78\% of the UK population over the age of 14 use the internet, $69 \%$ of whom utilise it to access healthrelated information. A 2011 Pew study (Fox, 2011) demonstrates that following email and product search, searching for health information is the third most common use of the internet by users. Social networks and mobile apps may have overtaken these functions since the 2011 study, yet using and sharing of health information has a prominent role in these emergent online functions (Fox and Duggan, 2013). Furthermore, these functions are increasingly utilised in health interventions (Free et al., 2013; Alvarez-Jimenez et al., 2014).

A sizeable body of literature have assessed the quality of online health information with respect to specific disease states. Their pattern of contribution to this area of inquiry has been twofold: to reaffirm the utility of the assessment tools, and to report weak to moderate quality health information for each respective disease state. A number of the studies are in the form of systematic reviews, such as for anxiety disorders (Ipser et al., 2007) and bladder pain syndrome (Tirlapur et al., 2013). However, these higher quality studies add little additional value in addressing the overarching problem. Within the extant body of literature, suggestions to address the widespread low quality of health information across digital media include developing disease-specific tools in 
contrast with generic assessment tools such as in multiple sclerosis (Harland and Bath, 2007), directing patients to validated, reliable and readable websites (Hanif et al., 2009; Aldairy et al., 2012; O'Neill et al., 2014), compensating the poor quality by directly educating patients (McKearney and McKearney, 2013), and enquiring about the type of online information patients acquire in order to clarify inaccuracies (Tirlapur et al., 2013). However, there is neither evidence for the widespread adoption of these suggestions, nor any objective improvements in the situation. The purpose of this study was to address the enduring and increasingly complex medical predicament of low quality online health information contributing to lay health knowledge and consequently to health literacy, health behaviours, and health-related decisions. We situate the predicament within its changing social and historical context, and conduct a purposeful quality assessment of online information on an indicative case study. We subsequently draw on and further test the application of social closure theory within a context of declining medical authority, in an attempt to derive tangible and actionable solutions to tackle the problem.

\section{Background}

The large-scale shift from collectivism to individualism has characterised the second half of twentieth century in the western world, and continues into the new millennium (Annandale and Field, 2001). Individualism entails the responsibility for one's own lifestyle choices, and in turn the blame for one's ill health. This inevitably leads to the individual's appetite and desire for endless information on health, beauty and wellbeing. Annandale and Field (2001) draw on the works of Giddens (1991) and Bauman (1987) to suggest that new social 
parameters of late modernity such as risk and uncertainty mandate individuals to actively construct identities, "amid a puzzling diversity of options and possibilities" (Giddens, 1991). Giddens suggests that we live in an information rich society in which life plans and strategies have to be negotiated via a potentially confusing mass of competing and sometimes contradictory sources of information (Hardey, 1999). In addition, the contemporary health-promoting neoliberal environment includes prioritising technologies of self-governance, embodied in online support groups, social networks, and health management mobile apps. These technologies of the self can be seen as a form of governmentality (Foucault, 1979), encouraging individuals to take care of themselves through self-monitoring, responsibility, choice and empowerment (Warin, 2011). Although such technologies empower individuals, they are within the paradigm of a governance of compliance, fulfilling government ends with neoliberal means of accountability to the individual (Rose, 1989). Collaterally, this has a domino effect on the power of the medical profession, whereby increased individual accountability for health can have an inverse relationship with the authority that the medical profession can wield in society. Such a trend can be traced in the findings of a 2013 Pew survey (Fox and Duggan, 2013), whereby $35 \%$ of U.S. adults report 'diagnosing' their medical condition online- a third of whom did not subsequently visit a clinician to get a professional opinion. The choice and user involvement policy agendas thus follow suit and provide novel challenges to the previously exclusive power and authority of the medical profession. An increased fear of uncertainty, enhanced sense of responsibility for the self, increasing perceptions of involvement and empowerment in clinical decision-making, and having a say (choice) in ones options for care and 
treatment are in tandem with the rise in the abundance of publicly accessible information and of internet usage.

The medical profession is founded on expert knowledge and mutual trust between the patient and the professional (Riska, 2001). Evidence-based medicine which underpins clinical decision-making was previously the exclusive jurisdiction of the medical professional. The Weberian notion of social closure can help explain this power dynamic, whereby certain social groups monopolize advantages by restricting access to resources and privileges to a limited circle of individuals. Various aspects of access to medical education, public accessibility to the medical language and sources of medical knowledge, and credentialist exclusion devices can be better understood as exercise of exclusionary closure by the medical profession (Parkin, 1979).

The evidence on diagnostic and treatment possibilities is now increasingly publicly accessible online, which weakens the knowledge hegemony of the medical profession. An inevitable consequence of this advance is the manner in which evidence is selectively collated and interpreted in different health information websites, news media, blogs, and social media, leading to variations and often contradictions in advice on specific treatment options. Further, with a Foucauldian knowledge-power perspective (Foucault, 1980), the internet opens the possibility to the promulgation of other modes of health knowledge and understanding of disease, which have been previously disqualified and excluded by the formalization and institutionalisation of medically sanctioned 'scientific' knowledge. 
Mutual trust is increasingly compromised with the dilution of the traditional knowledge-power relations in the doctor-patient relationship, when aspects of expert knowledge along with alternative forms of health knowledge become widely available across digital media. Mechanic (2005) asserts that "better educated and more sophisticated patients can contribute to meaningful doctorpatient relationships, but some of the information now readily available raises doubts and feelings of insecurity about the motives and behavior of medical providers and institutions". Patients begin to question the judgment of the medical professional, leading to an eventual transformation in the identity and function of the medical professional characterised by an ensuing decline in their authoritative clinical decision-making.

We are thus witnessing a radical transformation in the doctor-patient relationship. As asserted by Horton (2003): “The fundamental change between past and present medicine is access to information. There used to be a steep information inequality between doctor and patient. No longer. As more people understand the risks as well as the benefits of modern medicine, we increasingly desire more information before we are willing to rely on trust to see us through. This need to be transparent about what doctors know (and what they do not), to engage in a consultation on closer to equal terms with patients, has changed the way medicine is practiced". Neuberger (2000) argues that if doctors are to continue to provide a service that meets the rising public expectations of the new 'educated patient', they need to develop new patient relationships, acting not as 
instructors but as guides, in order to help people make decisions about their own health.

Hardey (1999) conducted a qualitative study of households who routinely used the internet to access health information and examined how it affected their health beliefs and behaviours. Hardey asserts that the information available via the internet transcends established scientific, political, and professional boundaries, and the virtual interactive opportunity creates the space for the construction of new narratives about health and lifestyle. He concluded that it is the users of information rather than authors or professional experts who decide what is delivered to them, thereby constructing their own lay health knowledge. Here a clear break is evident from print-based health information, for which the health professionals controlled the content and flow of information (Hardey, 1999). The emergence of online digital media has facilitated the promulgation and access to alternative explanations of disease, including lay explanations. Lay health knowledge can also be conceived as experiential knowledge, defined as implicit, lived experiences of individual patients with their bodies and their illnesses as well as with care and cure. Experiential knowledge arises when these experiences are converted into a personal insight that enables a patient to cope with individual illness and disability (Caron-Flinterman et al., 2005). There is now a growing trend in the broadcasting of experiential knowledge via online forums, social media, video-sharing and dedicated websites. The 2013 Pew survey (Fox and Duggan, 2013) reported that a quarter of internet users have read or watched someone else's experience about health or medical issues. 
In tracing the literature during the 1979-2002 period, Prior (2003) observed a changing trend from a focus on 'lay health beliefs' to a focus on 'lay health knowledge and expertise'. It can be argued that the emerging prominence and legitimacy of lay health knowledge has been facilitated by the internet, and is due to a surge in broadcasting of experiential knowledge coupled with an increased access to and enactment of medical and non-medically sanctioned online information on health and illness. We propose that the medical profession acknowledge the prevailing legitimacy of lay health knowledge coupled with the reality of their declining authority in society. We further suggest, with a usurpationary closure perspective, that the medical profession attempt to positively influence lay health knowledge in consonance with their objective of improving clinical outcomes. To this end, the following section presents a purposeful conventional quality assessment of online health information as a source of lay health knowledge, using an indicative case study. We further test the application of social closure theory on the findings of the case study, and also present its extant application on experiential knowledge, in order to demonstrate a constructive re-enactment of the closure of the medical profession on medical knowledge.

\section{Case study: Apicectomy}

Apicectomy is a surgical procedure performed by an oral surgeon, which involves removal of the root end of a tooth and the surrounding infective tissue. It is performed for teeth that are not deemed clinically appropriate for conventional root canal treatment and in cases of recurrent infection. In such circumstances, Apicectomy is promoted by clinicians as the last resort to keeping 
ones tooth, which has functional, emotional, and aesthetic implications. Many patients experience difficulties in accepting the loss of their teeth, feel inhibited in carrying out everyday activities such as chewing and speaking, feel less confident about themselves, and less able to accept the inevitable change in facial shape which can occur following the loss of teeth (Davis et al., 2000). In a systematic review of the literature, Gerritsen et al. (2010) provide rigorous evidence that tooth loss is associated with impairment in oral health-related quality of life (OHRQoL), and conclude by suggesting that there will be greater demand from patients for treatments aimed at preserving teeth.

Apicectomy has a disparate success rate of 45-95\% (Evans et al., 2012), and oral surgeons need to apply stringent criteria for a clinical decision to perform the operation. It results in collateral damage to the underlying bone structure, and in cases that the procedure fails, the patient will require a bone graft if they decide to replace the lost tooth with a dental implant. This corresponds to extra cost, further lengthy surgery, and more pain and inconvenience for the patient. Clinical experience of one of the authors in consultation appointments suggests that some patients are fervently opinionated on Apicectomy being the only treatment possibility, in a quest to keep their tooth. Upon further inquiry, their obstinacy can normally be traced to online information. When the treatment is ultimately deemed inappropriate by the clinician, such patients express their disappointment and dissatisfaction, which consequently affects the doctorpatient relationship. Conversely, another group of challenging patients are those who refuse Apicectomy, citing experiences of family and friends, or online blogs of others who have had a negative experience. In some cases, such cited 
experiences vaguely refer to general oral surgery unrelated specifically to Apicectomies, considering that the latter is not a routine procedure. This is often disheartening to clinicians as they lament the eventual loss of a tooth that had the potential to be saved.

\section{Assessing quality of online health information}

Many instruments have been developed to assess the quality and accuracy of online health information, and a review of the literature (Bernstam et al., 2005) identified 273 such tools. Three of the most utilised instruments (Fahy et al., 2014) will be referred to herein, along with a brief justification of the instrument of choice to evaluate our indicative case study. HONcode is one of the earlier quality evaluation tools, created by the Health on the Net Foundation (HON) in 1995. It consists of an 8-point code of conduct that relate to ethics of the information provided. Approved websites can display an accreditation seal which is subject to a process of annual review by the HON Foundation (HON, 2015). JAMA (Journal of the American Medical Association) Benchmark was first introduced in 1997 (Silberg et al., 1997), and provides a set of criteria for qualitatively assessing and evaluating health information. The DISCERN instrument (Charnock et al., 1999) is a validated tool and consists of 16 questions assessing reliability and quality of healthcare information for patients.

HONcode is related more to the ethics rather than the accuracy of the medical information provided. Furthermore, continued compliance with the HON code of conduct is not systematically enforced, and a study found that none of the websites identified displaying a HON seal complied with all 8 criteria (Meric et 
al., 2002). It is worthy of noting the concern that such website validation and accreditation schemes pose important challenges of profiteering and conflicts of interest. Another study found that websites that met none of the JAMA benchmarks nor included the HON seal contained less inappropriate treatment recommendations than those that met all the benchmarks and displayed the HON seal (Barker et al., 2010). Such assessment tools cannot have implicit value independent of the researcher/examiner, as their judgement will in effect determine the outcome of the assessment. Further, an expert judgement made on the quality and accuracy of a website content using these evaluation tools can serve as an instrument of exercising power and exclusionary closure on websites that have not been assessed in such manner. In the absence of regulation and standardisation, these tools can provide the means of exercising arbitrary power on information sources at the expense of other competing digital media. However, it is also important to take into account the public perception of such validation measures, and no studies have been identified which investigate the recognition and legitimacy bestowed on such validation measures by the public.

The DISCERN instrument provides a relative advantage of having been developed with public involvement, suggesting the incorporation of expert and lay insights into its development. Multiple national samples of the public were asked to assess written information during the development of the tool, giving rise to good inter-examiner agreement (Charnock et al., 1999). Furthermore, the finalised DISCERN instrument has been applied and validated in many different contexts and study samples (Khazaal et al., 2012). The DISCERN instrument includes components assessing website bias, benefits of each treatment, risks of 
each treatment, information on alternative treatments, relevance, areas of uncertainty, and overall quality.

\section{Methods}

The objectives of the case study was to review the information readily available to patients on the internet for Apicectomy and to assess their quality using the DISCERN instrument. Google is consistently the most visited website and the most utilised search engine in the world (Alexa, 2015). The Google search engine was accessed on 20th March 2014 in English using the terms "apicectomy", "endodontic microsurgery" and "root end surgery". We decided to examine the search results of the first seven pages as this equates to the pages viewed by $95 \%$ of the users of search engines on the internet (Jansen et al., 2005). Two dentally qualified reviewers with good academic understanding of Apicectomies and similar clinical experience independently hand-searched the first seven pages of the results yielded by Google. Websites providing information on the Apicectomy procedure were included in the study. Any sponsored links, news articles, video feeds, discussion groups, sites without full public access (such as academic journals), and duplicate sites were excluded from the study.

The DISCERN instrument was used to assess the quality of the online information on Apicectomy by each reviewer independently. The questions are categorised into three sections. The first section assesses the reliability of the information, the second section addresses the specific details of treatment options and the third section relates to the overall quality rating of the 
publication (Charnock, 1998). Each question is graded with a score of 1 to 5 ; 1 is regarded as a 'definite no' and 5 is defined as a 'definite yes'. Based on the DISCERN scores, the overall quality of websites was further categorised into groups of excellent (scores of 63-75), good (51-62), fair (39-50), poor (27-38), and very poor (15-26) content. The maximum DISCERN score is 75 for excellent quality, and minimum score is 15 for poor quality. The collected data from the DISCERN instrument was entered into Microsoft Excel and analysed using MedCalc.

\section{Results}

15 websites met the study criteria from the first 7 pages (70 search results) of the links generated by the Google search engine for each keyword search. The order of search results, overall mean DISCERN score, and quality ranking of the findings are shown in Table 1. The ranking goes up to 14, as two websites shared the quality rank of 6 .

\section{TABLE 1 ABOUT HERE}

Out of the maximum of 75 points, the mean DISCERN score was 39.8 (SD 7.25). The average website in this sample is therefore categorised as being of 'fair quality'. The highest DISCERN score was 52.5, ranked as 'good', by the Colgate website and the lowest score was 28.5, ranked as 'poor', by the Wikipedia website. Of all the websites rated, no website was found to be 'excellent', 6.67 percent $(n=1)$ was found to be 'good', 46.67 percent $(n=7)$ were 'fair', 46.47 percent ( $n=7)$ were 'poor', and no websites were found of 'very poor' quality. 
TABLE 2 ABOUT HERE

The mean kappa value was 0.842, calculated with MedCalc (Table 2). This indicates 'very good' agreement (Altman, 1991) between the two reviewers. Our findings demonstrate Google search results in one time period. Many websites are dynamic and regularly updated, and their popularity and ranking changes continuously. Furthermore, there is an emerging trend of employing customization technologies by search engines like Google. Considering these factors, our results will not be replicable. This can be deemed as a limitation of the present case study, although our objective was not to provide a definitive list of reliable websites for Apicectomy. Another limitation of our study is that we confined our search to the Google search engine. Although Google is the most utilized search engine online (Alexa, 2015), it may have been possible to miss important websites visited by the public. In addition, the narrow criteria of excluding video links, discussion groups and social networks may have resulted in overlooking important emerging sources of lay health knowledge.

\section{Discussion}

The case study findings largely confirm research in this area from other medical specialties, which point to a 'medical' crisis of inaccurate and alternative forms of health information on the internet contributing to lay health knowledge, and consequently to doctor-patient relationships and clinical outcomes. 15 Google search results from the first 70 were found to have relevant information and 
were included in the quality assessment. Out of the 15 websites, none were of 'excellent quality', one was 'good quality', seven had 'fair quality', and seven had 'poor quality'. Thus within the circumstances of our case study, the chance of a patient accessing a website with fair or good quality information on Apicectomies is $11 \%$ ( 8 out of 70 ). The public may well visit any of the other $89 \%$ of websites, with potentially inaccurate medical information that will shape their decision on how to deal with Apicectomies. It is worth noting that this is a generous assessment of the situation, as our analysis included the first 70 websites (seven pages) of search results, yet other studies (Eysenbach and Kohler, 2002) have found that most internet users only visit the top 10 websites (first page) of the search results. Of particular concern was our finding of no discernable difference in quality of websites authored by specialists compared to those with unspecified author credentials. Potential clinical consequences of the poor quality medical information on Apisectomies can include deferral of treatment resulting in the loss of a tooth that had the potential to be saved. Conversely, a patient's false expectations of preserving a tooth that is of poor prognosis can have adverse consequences for the doctor-patient relationship.

As outlined earlier, the extant literature has suggested a number of avenues to address the enduring and increasingly complex medical predicament of inaccurate and alternative forms of health knowledge online. However, these suggestions do not adequately tackle the problem and have many feasibility impediments, evident in them not having been universally adopted. Developing disease specific tools to assess health information quality more accurately does not address the core problem. Website validation and accreditation schemes 
pose important challenges of profiteering, conflicts of interest, adoption, and enforcement, considering that regulation of websites for health information content is inconceivable. Calls for combating poor health information with enhanced traditional doctor-patient consultations is also far from a solution, and suggests a disconnect with the emerging trend of the legitimacy of lay health knowledge.

\section{Closure as a potential solution}

A potential solution to the medical predicament of poor quality online health information can be expressed with the Weberian notion of social closure -a process by which social groups monopolize advantages by restricting access to resources, privileges and opportunities to a limited circle of eligibles. Parkin (1979) extended closure theory by arguing that closure strategies would include not only those of an exclusionary kind, but also those adopted by the excluded themselves as a direct response to their status as outsiders. This is in line with Weber et al. (1978), who acknowledges that: "Such group action may provoke a corresponding reaction on the part of those against whom it is directed". Parkin (1979) thus proposes two reciprocal modes of closure- exclusionary and usurpationary- with both being means for mobilizing power to enhance a group's share of rewards or resources. Exclusionary closure is the attempt by one group to secure for itself a privileged position at the expense of some other group through a process of subordination. Usurpationary closure is mounted by a group in response to its outsider status and the collective experiences of exclusion. Usurpationary actions have in common the aim of biting into the resources and benefits accruing to dominant groups in society. Usurpationary closure, as 
Parkin argues, is always a consequence of, and a collective response to exclusion. The intended scale of usurpation can range from marginal redistribution to complete expropriation (Parkin, 1979).

Exclusionary and usurpationary closure are exercised distinctively by groups in polar positions of social stratification, such as social classes. However, Parkin argues that some groups adopt dual modes of closure in which they primarily use one mode of closure practice but supplement it with the opposite mode. In explaining his concept of Dual closure, Parkin (1979) provides the example of the teacher who relies primarily on credentialist exclusion devices in an attempt to attain professional status, but in addition employs the usurpation strategies of organised labour (Murphy, 1986). Usurpationary closure can signify the evolution of the status of allied health professionals and 'para-professionals' in relation to the medical profession (Larkin, 1983; Holloway et al., 1986; Witz, 1990; Nancarrow and Borthwick, 2005; Hollenberg, 2006; Traynor et al., 2015). It can also be argued that from a usurpationary closure perspective, the public, via the internet, have been biting into the medical profession's monopoly on medical knowledge, and eroding their exclusionary closure with respect to power, autonomy and self-regulation. Closure theory can explain the role of 'doctor rating' websites on the decline in autonomy and the inevitable rise in regulation and monitoring of the medical profession. It can also be argued that the internet has challenged the closure on medical education by a limited number of medical schools, by facilitating provision of distance learning courses, and increasing the number of outlets that offer medical education. 
The emerging significance of lay health knowledge was reported as early as the 1970s, when self-help groups were perceived to threaten the closure of certain professional groups, and substitute professional authority with experiential authority (Borkman, 1976). Lay health knowledge poses a significant challenge to the once dominant knowledge of the medical profession, as the increasingly broadcast and embraced experiential knowledge, coupled with appropriation of widely accessible health-related information by patients, leads to endless possibilities of alternative narratives to illness description and treatment options. In addition, patient experience has become an essential indicator of the performance of health care organisations alongside efficiency, safety and clinical outcomes (Coulter et al., 2009). Attention on patient compliance and adherence has progressively transitioned into attention for activation and involvement of patients (Morrow et al., 2013). In recent years, virtual communities, including patient-to-patient and patient-to-doctor online health communities have rapidly increased in prevalence. A study of the latter demonstrates that patients' value of medical knowledge was tantamount to experiential knowledge (Vennik et al., 2014).

The current landscape thus suggests the following to the medical profession: an expanding trend in the broadcasting and accessibility of experiential knowledge; an exponential rise in the interest in and development of unsolicited health information websites and other digital media content with medically inaccurate and alternative forms of health knowledge; and the ensuing decline of dominance and power of the medical profession. A constructive response to such circumstances by the profession can be articulated with the notion of 
usurpationary closure. This would entail an endeavor by the medical profession to exercise dual closure. Parallel to their traditional but declining custom of exclusionary closure, medical doctors can strive to bite into the prevailing lay health knowledge, and utilize usurpationary closure to influence the public with what the specialist community deem as accurate medical information for health concerns within their remit. Such soft governance effort does not infringe on the choice of patients, nor does it enforce a particular source of knowledge. It involves an attempt by medical specialists to discover online digital sources actively contributing to lay health knowledge in their respective discipline, and strive to contribute to and adapt these sources to increase the objective medical quality and accuracy of their content. Closure is historically linked to the exercise of dominance and subordination, and suggestion for its adoption can appear controversial. However, Frank Parkin's development of the theory and his conception of dual closure enables it to be applied constructively to the limits (Prior, 2003) of the prevailing lay health knowledge. In reviewing the medical sociology literature, Prior discusses the paradoxical notion of lay expertise. The author contends that lay people may have have knowledge to impart by way of experience of illness, but are not skilled or practiced in the diagnosis and management of illness. Experiential knowledge is viewed as idiosyncratic and invariably limited, and it is suggested that the virtues of expertise should be acknowledged. Furthermore, although the application of medical knowledge has been viewed as an instrument to exercise power (Foucault, 1980), it can be rigorously argued that this form of knowledge has, at the very least, some degree of objective authenticity and legitimacy independent of the arguably inflated credibility that has traditionally been given to judgments (diagnosis) stemming 
from this knowledge. These arguments can provide a basis for exercising soft closure on the Foucauldian instrument of dispersion (Farrell and Lillis, 2013) of lay health knowledge exemplified in experiential knowledge outlets and health information digital media content. Medical specialists can thus exercise such soft closure to contribute to and attempt to validate both experiential knowledge and health information in digital media, which can influence lay health knowledge and may prove to be a feasible and pragmatic strategy for more meaningful doctor-patient relationships, enhanced collaborative clinical decision-making, and eventually improved clinical outcomes.

\section{Current application of closure to experiential knowledge}

An extant application of soft closure on lay health knowledge can be observed in the model followed by Healthtalkonline.org, which is a website that collates a "reliable" set of experiential knowledge on health and illness. The website was found in 2001 by medical researchers and practitioners at the University of Oxford. It has been promoted by established professional institutions (e.g. Royal Society of Medicine) and has the support of a number of celebrities and media outlets, advocating its accuracy and reliability. The online resource has a multimedia database of qualitative interviews, broadcasting the experiences of health and illness of over 2,000 people and covering over 40 different conditions (Newman et al., 2009). It provides patients, families and healthcare professionals with medically reliable information about conditions, treatment choices and support options via the selected experiences and personal stories of others. In a video interview promoting Healthtalkonline, a medical consultant at Hammersmith Hospital (Sikora, n.d.) states: "the great thing about this site is that 
it is validated, you know you can trust it, it's been gone through very carefully, its factually correct, and there are no extremists in there who are telling information that really is not true". Such discourse resonates vociferously with the knowledge-power complex and the exclusion of alternative and medically inaccurate knowledge. The website can be viewed as a form of closure - by the medical profession - on the numerous narratives of experiential knowledge. It exercises usurpationary closure on experiential knowledge, validating parts of this knowledge and excluding the lay narratives that are unacceptable to current medical understanding, therefore presenting to the public an "official" and "reliable" source of lay health knowledge. Utilising this outlet, the medical community attempt to exercise soft power and governance on a prominent instrument of dispersion of lay health knowledge, drawing on a number of resources and strategies to legitimise such effort.

\section{Exercising closure on health information}

While Healthtalkonline exercises soft closure on experiential knowledge, such an approach can also be pursued for publicly accessible health information across digital media. A number of problem areas can be identified within the Apicectomy case study findings, which can be targeted with a soft closure approach. The particular results to focus on are the Order of search results and the Quality rank:

Wikipedia is the first search result, but has a low quality rank (12 out of 14). In line with calls in the British Medical Journal for medical specialists to engage with Wikipedia more constructively (Kint and Hart, 2012), Apicectomy 
specialists can embark on revising the content of the Wikipedia pages to increase the medical accuracy and quality of the information provided. Due to Wikipedia being a user-generated encyclopaedic and reference source, specialists can include links to other validated websites in this area. Further, they can actively contribute to other important lay health knowledge outlets such as Healthtalkonline, and place a link on the Wikipedia page.

Baoms.org.uk and Aae.org are websites for professional associations related to Apicectomies. They were the third and fourth search results respectively, and so appeared in the first two pages of the search results. However, the quality rank was 6 and 7 respectively, equating to 'fair quality' in terms of DISCERN scores. This is a disappointing finding, as we would expect websites for professional medical associations to have high quality information on the disease states within their remit. This is another target which Apicectomy specialists can address and revise, influencing the quality of health information potentially accessed by patients that contribute to lay health knowledge. Baos.org.uk is a website for another professional association related to Apicectomies. It is the last website in the order of search results, yet it has a high quality rank (2 out of 14), although this still equates to 'fair quality' with respect to DISCERN scores. Apicectomy specialists can employ strategies such as search engine optimisation in order for this website to appear on the first page of search results. It is however needless to say that they should also take steps to improve the medical quality of such information. 
The above application of usurpationary closure to optimise online health information is a demonstration of pragmatic action that can be taken by medical professionals to positively influence lay health knowledge. Practitioners in other specialities can follow this approach, with potentially positive impact on doctorpatient relationships and on clinical outcomes. The actions to be taken- whether contributing to an online encyclopaedia, commenting in a blog or social network, increasing quality of information on a professional association website, or developing a mobile app- is wholly contingent on the targets identified by the specialist community in their respective research for quality of online health information.

\section{Conclusion}

The internet has facilitated the usurpationary closure of the public on health knowledge which was previously the exclusive jurisdiction of the medical profession. Such closure has been exercised via two parallel avenues: increasing accessibility and enactment of medical and non-medically sanctioned online information on health and illness, and the exponential broadcasting of experiential knowledge. These two avenues contribute to the emerging prominence and legitimacy of lay health knowledge on par with medical knowledge.

Our case study to assess the quality of online health information relating to Apicectomies confirmed findings from previous literature, which stress the crisis of inaccurate online health information from a biomedical perspective. Moreover, the solutions proposed in the literature for this predicament have many 
feasibility impediments and have not improved the situation. We propose that the previous closure of the medical professional on medical knowledge can now be re-enacted in more constructive ways. Namely, acceptance of the prevailing legitimacy of lay health knowledge, and positive exercise of usurpationary closure in an attempt to enhance the medical quality of lay health knowledge. Although closure has been historically associated with dominance and subordination, Frank Parkin's extension of the theory, and our proposed application of such soft closure to lay health knowledge may prove beneficial. The example of Healthtalkonline.org demonstrates the extant application of soft closure to collate a medically reliable set of experiential knowledge on a range of health issues. Testing of the proposition on our case study of Apicectomies demonstrates targeted, feasible and potentially beneficial solutions to increasing the medical quality of online health information. Such exercise of soft closure can be adopted by other medical specialties, potentially resulting in more meaningful doctor-patient relationships, nurturing collaborative clinical decision-making with the better-informed patient, and improved clinical outcomes. The dialectic of exclusionary/usurpationary closure and the adoption of dual modes of closure to varying degrees by the same social group can be relevant to the wider social inquiry of health. Such perspective can complement the widely utilised Foucauldian knowledge-power complex in understanding the changing power dynamics between the multiple level of actors in health and healthcare.

\section{Word Count: 6176}




\section{References}

Aldairy, T., Laverick, S. \& McIntyre, G. T. 2012. Orthognathic surgery: is patient information on the Internet valid? European Journal of Orthodontics, 34, 4, 466469.

Alexa. 2015. Top Sites- The top 500 sites on the web [Online]. Accessed 20th February 2015: http://www.alexa.com/topsites.

Altman, D. G. 1991. Practical statistics for medical research, London ; New York, Chapman and Hall.

Alvarez-Jimenez, M., Alcazar-Corcoles, M. A., Gonzalez-Blanch, C., Bendall, S., McGorry, P. D. \& Gleeson, J. F. 2014. Online, social media and mobile technologies for psychosis treatment: A systematic review on novel user-led interventions. Schizophrenia Research, 156, 1, 96-106.

Annandale, E. \& Field, D. 2001. Medical Sociology in Great Britain. In: COCKERHAM, W. C. (ed.) The Blackwell Companion to Medical Sociology. Malden: Blackwell Publishing.

Barker, S., Charlton, N. P. \& Holstege, C. P. 2010. Accuracy of Internet Recommendations for Prehospital Care of Venomous Snake Bites. Wilderness \& Environmental Medicine, 21, 4, 298-302.

Bauman, Z. 1987. Legislators and interpreters : on modernity, post-modernity, and intellectuals, Cambridge, Polity Press

Bernstam, E. V., Shelton, D. M., Walji, M. \& Meric-Bernstam, F. 2005. Instruments to assess the quality of health information on the World Wide Web: what can our patients actually use? International Journal of Medical Informatics, 74, 1, 13-19.

Borkman, T. 1976. Experiential knowledge: a new concept for the analysis of selfhelp groups. Social Services Review, 50, 3, 445-456.

Caron-Flinterman, J. F., Broerse, J. E. W. \& Bunders, J. F. G. 2005. The experiential knowledge of patients: a new resource for biomedical research? Social Science \& Medicine, 60, 11, 2575-2584.

Charnock, D. 1998. The DISCERN Handbook, Abingdon, Radcliffe Medical Press.

Charnock, D., Shepperd, S., Needham, G. \& Gann, R. 1999. DISCERN: an instrument for judging the quality of written consumer health information on treatment choices. Journal of Epidemiology \& Community Health, 53, 2, 105-111.

Coulter, A., Fitzpartrick, R. \& Cornwell, J. 2009. Measures of patients' experience in hospital: purpose, methods and uses. London: The King's Fund.

Davis, D. M., Fiske, J., Scott, B. \& Radford, D. R. 2000. Prosthetics: The emotional effects of tooth loss: a preliminary quantitative study. Br Dent J, 188, 9, 503-506.

Dutton, W. H. \& Blank, G. 2013. Cultures of the Internet: The Internet in Britain Oxford Internet Survey 2013. University of Oxford: Oxford Internet Institute.

Evans, G. E., Bishop, K. \& Renton, T. 2012. Update of guidelines for surgical endodontics - the position after ten years. British Dental Journal, 212, 10, 497498.

Eysenbach, G. \& Kohler, C. 2002. How do consumers search for and appraise health information on the world wide web? Qualitative study using focus groups, usability tests, and in-depth interviews. British Medical Journal, 324, 7337, 573577. 
Fahy, E., Hardikar, R., Fox, A. \& Mackay, S. 2014. Quality of patient health information on the Internet: reviewing a complex and evolving landscape. Australasian Medical Journal, 7, 1, 24-28.

Farrell, C. T. \& Lillis, J. P. 2013. An adaptation to Michel Foucault's medical authority: The Lucid Succor of the informal caregiver. Social Theory \& Health, 11, 4, 327-343.

Foucault, M. 1979. On Governmentality. Ideology and Consciousness, 6, 1, 5-22.

Foucault, M. 1980. Power/Knowledge: Selected Interviews and Other Writings 19721977, Brighton, Harvester Press.

Fox, S. 2011. The Social Life of Health Information 2011. Pew Internet and American Life Project. Washington D.C.: Pew Research Center.

Fox, S. \& Duggan, M. 2013. Health Online 2013. Pew Internet and American Life Project. Washington D.C.: Pew Research Center.

Free, C., Phillips, G., Galli, L., Watson, L., Felix, L., Edwards, P., Patel, V. \& Haines, A. 2013. The Effectiveness of Mobile-Health Technology-Based Health Behaviour Change or Disease Management Interventions for Health Care Consumers: A Systematic Review. Plos Medicine, 10, 1, Doi: ARTN e1001362

1001310.1001371/journal.pmed.1001362.

Gerritsen, A. E., Allen, P. F., Witter, D. J., Bronkhorst, E. M. \& Creugers, N. H. J. 2010. Tooth loss and oral health-related quality of life: a systematic review and meta-analysis. Health and quality of life outcomes, 8, 126, doi: 10.1186/14777525-1188-1126.

Giddens, A. 1991. Modernity and self-identity : self and society in the late modern age, Stanford, Calif., Stanford University Press.

Hanif, F., Read, J. C., Goodacre, J. A., Chaudhry, A. \& Gibbs, P. 2009. The role of quality tools in assessing reliability of the internet for health information. Informatics for Health \& Social Care, 34, 4, 231-243.

Hardey, M. 1999. Doctor in the house: the Internet as a source of lay health knowledge and the challenge to expertise. Sociology of Health \& Illness, 21, 6, 820-835.

Harland, J. \& Bath, P. 2007. Assessing the quality of websites providing information on multiple sclerosis: evaluating tools and comparing sites. Health Informatics Journal, 13, 3, 207-221.

Hollenberg, D. 2006. Uncharted ground: Patterns of professional interaction among complementary/alternative and biomedical practitioners in integrative health care settings. Social Science \& Medicine, 62, 3, 731-744.

Holloway, S. W. F., Jewson, N. D. \& Mason, D. J. 1986. Reprofessionalization or Occupational Imperialism - Some Reflections on Pharmacy in Britain. Social Science \& Medicine, 23, 3, 323-332.

HON. 2015. Operational definition of the HONcode principle [Online]. Accessed 10th February 2015: http://www.hon.ch/HONcode/Guidelines/guidelines.html.

Horton, R. C. 2003. Second opinion : doctors, diseases, and decisions in modern medicine, London, Granta Books.

Ipser, J. C., Dewing, S. \& Stein, D. J. 2007. A systematic review of the quality of information on the treatment of anxiety disorders on the internet. Current Psychiatry Reports, 9, 4, 303-309.

ITU 2014. The World in 2014: ICT Facts \& Figures. Geneva: International Telecommunications Union (ITU), April 2014. 
Jansen, B. J., Spink, A. \& Pedersen, J. 2005. A temporal comparison of AltaVista Web searching. Journal of the American Society for Information Science and Technology, 56, 6, 559-570.

Khazaal, Y., Chatton, A., Zullino, D. \& Khan, R. 2012. HON label and DISCERN as content quality indicators of health-related websites. Psychiatric Quarterly, 83, 1, $15-27$.

Kint, M. \& Hart, D. P. 2012. Should clinicians edit Wikipedia to engage a wider world web? British Medical Journal, 345, e4275, Doi: 10.1136/bmj.e4275.

Larkin, G. 1983. Occupational monopoly and modern medicine, London ; New York, Tavistock Publications.

McKearney, T. C. \& McKearney, R. M. 2013. The quality and accuracy of internet information on the subject of ear tubes. International journal of pediatric otorhinolaryngology, 77, 6, 894-897.

Mechanic, D. 2005. Changing Medical Organisation and the Erosion of Trust. In: CONRAD, P. (ed.) The Sociology of Health \& Illness: Critical Perspectives. New York: Woth Publishers.

Meric, F., Bernstam, E. V., Mirza, N. Q., Hunt, K. K., Ames, F. C., Ross, M. I., Kuerer, H. M., Pollock, R. E., Musen, M. A. \& Singletary, S. E. 2002. Breast cancer on the world wide web: cross sectional survey of quality of information and popularity of websites. British Medical Journal, 324, 7337, 577-581.

Morrow, E., Cotterell, P., Robert, G., Grocott, P. \& Ross, F. 2013. Mechanisms can help to use patients' experiences of chronic disease in research and practice: an interpretive synthesis. Journal of Clinical Epidemiology, 66, 8, 856-864.

Murphy, R. 1986. Weberian Closure Theory - a Contribution to the Ongoing Assessment. British Journal of Sociology, 37, 1, 21-41.

Nancarrow, S. A. \& Borthwick, A. M. 2005. Dynamic professional boundaries in the healthcare workforce. Sociology of Health \& Illness, 27, 7, 897-919.

Neuberger, J. 2000. The educated patient: new challenges for the medical profession. Journal of internal medicine, 247, 1, 6-10.

Newman, M. A., Ziebland, S. \& Barker, K. L. 2009. Patients' views of a multimedia resource featuring experiences of rheumatoid arthritis: pilot evaluation of http://www.healthtalkonline.org. Health Informatics Journal, 15, 2, 147-159.

O'Neill, S. C., Baker, J. F., Fitzgerald, C., Fleming, C., Rowan, F., Byrne, D. \& Synnott, K. 2014. Cauda equina syndrome: assessing the readability and quality of patient information on the Internet. Spine (Phila Pa 1976), 39, 10, E645-649.

Parkin, F. 1979. Marxism and class theory : a bourgeois critique, New York, Columbia University Press.

Prior, L. 2003. Belief, knowledge and expertise: the emergence of the lay expert in medical sociology. Sociol of Health \& Illness, 25, 3, 41-57.

Riska, E. 2001. Health Professions and Occupations. In: COCKERHAM, W. C. (ed.) The Blackwell Companion to Medical Sociology. Malden: Blackwell Publishing.

Rose, N. 1989. Governing the Soul: The Shaping of the Private Self, London, Routledge.

Sikora, K. n.d. 'What people say about us'- Promotional video interview [Online]. Healthtalkonline: http://www.healthtalk.org/peoples-experiences. [Accessed 23rd February, 2015 2015].

Silberg, W. M., Lundberg, G. D. \& Musacchio, R. A. 1997. Assessing, controlling, and assuring the quality of medical information on the Internet: Caveant lector et viewor--Let the reader and viewer beware. Journal of the American Medical Association (JAMA), 277, 15, 1244-1245. 
Tirlapur, S. A., Leiu, C. \& Khan, K. S. 2013. Quality of information on the internet related to bladder pain syndrome: a systematic review of the evidence. International Urogynecology Journal, 24, 8, 1257-1262.

Traynor, M., Nissen, N., Lincoln, C. \& Buus, N. 2015. Occupational closure in nursing work reconsidered: UK health care support workers and assistant practitioners: A focus group study. Social Science \& Medicine, 136-137, July 2015, 81-88.

Vennik, F. D., Adams, S. A., Faber, M. J. \& Putters, K. 2014. Expert and experiential knowledge in the same place: patients' experiences with online communities connecting patients and health professionals. Patient education and counseling, 95, 2, 265-270.

Warin, M. 2011. Foucault's progeny: Jamie Oliver and the art of governing obesity. Social Theory \& Health, 9, 1, 24-40.

Weber, M., Roth, G. \& Wittich, C. 1978. Economy and society : an outline of interpretive sociology, Berkeley, University of California Press.

Witz, A. 1990. Patriarchy and Professions - the Gendered Politics of Occupational Closure. Sociology-the Journal of the British Sociological Association, 24, 4, 675-690. 


\begin{tabular}{|c|c|c|c|}
\hline $\begin{array}{l}\text { Order of } \\
\text { search } \\
\text { results }\end{array}$ & Website Address & $\begin{array}{l}\text { Mean } \\
\text { score }\end{array}$ & $\begin{array}{l}\text { Quality } \\
\text { Rank }\end{array}$ \\
\hline 1 & http://en.wikipedia.org/wiki/Apicoectomy & 32 & 12 \\
\hline 2 & $\begin{array}{l}\text { http://www.colgate.com/app/CP/US/EN/OC/Infor } \\
\text { mation/Articles/Oral-and-Dental-Health- } \\
\text { Basics/Common-Concerns/Gum- } \\
\text { Disease/article/Apicoectomy.cvsp\#part8 }\end{array}$ & 52.5 & 1 \\
\hline 3 & http://www.baoms.org.uk/file.aspx?id=58 & 43 & 6 \\
\hline 4 & $\begin{array}{l}\text { http://www.aae.org/patients/treatments-and- } \\
\text { procedures/endodontic-surgery-explained.aspx\#2 }\end{array}$ & 40.5 & 7 \\
\hline 5 & http://dentalcarematters.com/apicoectomy/ & 34.5 & 10 \\
\hline 6 & $\begin{array}{l}\text { http://www.toothology.net/content/default.asp?inte } \\
\text { rest_id=2\&nav_id=14567\&article_id=1948\&sid=B } \\
\text { 91334905D2C47F892B164D5806B5253 }\end{array}$ & 35.5 & 9 \\
\hline 7 & http://www.dentanet.org.uk/public/apicetomy.html & 34 & 11 \\
\hline 8 & http://www.dentalfind.com/info/apicoectomy\#b & 46 & 4 \\
\hline 9 & http://www.dental-surgery-4you.eu/wsr2.htm & 43 & 6 \\
\hline 10 & $\begin{array}{l}\text { http://www.qualitydentistry.com/dental/endo/apico } \\
\text { ectomy.html }\end{array}$ & 31 & 13 \\
\hline 11 & http://lcdcdental.com/Portals/0/apicoectomy.pdf & 47 & 3 \\
\hline 12 & http://www.1800dentist.com/apicoectomy/ & 36 & 8 \\
\hline 13 & $\begin{array}{l}\text { http://en.wikipedia.org/wiki/Microsurgical_endodo } \\
\text { ntics }\end{array}$ & 28.5 & 14 \\
\hline 14 & $\begin{array}{l}\text { http://endopracticeus.com/web/home/clinical/332- } \\
\text { excellence-in-endodontics-endodontic- } \\
\text { microsurgery.html }\end{array}$ & 45 & 5 \\
\hline 15 & $\begin{array}{l}\text { http://www.baos.org.uk/resources/Apicectomy1.pd } \\
\mathrm{f}\end{array}$ & 48.5 & 2 \\
\hline
\end{tabular}

Table 1: Quality ranking of websites based on DISCERN scores

\begin{tabular}{|c|c|c|c|c|c|c|}
\hline & \multirow{2}{*}{$\begin{array}{c}\text { Reviewer } \\
\mathbf{1}\end{array}$} & $\begin{array}{c}\text { Reviewer } \\
\mathbf{2}\end{array}$ & $\begin{array}{c}\text { Percent of } \\
\text { maximum } \\
\text { possible } \\
\text { score }\end{array}$ & Kappa & Lower & Upper \\
\cline { 4 - 7 } & & & 53.01 & 0.842 & 0.734 & 0.951 \\
\hline $\begin{array}{c}\text { DISCERN } \\
\text { score }\end{array}$ & $40 \pm 7.23$ & $39.6 \pm 7.51$ & & & & \\
\hline \multicolumn{2}{|l|}{} & & & & & \\
\hline Standard error & 0.055 & & & & & \\
\hline
\end{tabular}

Table 1: Test of agreement between reviewers 